Supplement of Atmos. Chem. Phys. Discuss., 14, 25051-25082, 2014

http://www.atmos-chem-phys-discuss.net/14/25051/2014/

doi:10.5194/acpd-14-25051-2014-supplement

(C) Author(s) 2014. CC Attribution 3.0 License.

(c) (i)

\title{
Carbonaceous aerosols on the south edge of the Tibetan Plateau: concentrations, seasonality and sources
}

\section{Z. Cong et al.}

Correspondence to: S. Kang (shichang.kang@itpcas.ac.cn) and K. Kawamura (kawamura@lowtem.hokudai.ac.jp) 
Table S1. The definition of different seasons at QOMS.

\begin{tabular}{cllcccc}
\hline \multirow{2}{*}{ Season } & \multicolumn{1}{c}{ Start Date } & End Date & Air Pressure & R.H. & Mean Temp. & Wind Speed \\
\cline { 2 - 6 } & \multicolumn{7}{c}{ (YYYY-MM-DD) } & $(\mathrm{hPa})$ & $(\%)$ & $\left({ }^{\circ} \mathrm{C}\right)$ & $(\mathrm{m} / \mathrm{s})$ \\
\hline \multirow{2}{*}{ Monsoon } & $2009 / 8 / 1$ & $2009 / 8 / 25$ & 606.25 & 55.26 & 12.39 & 6.51 \\
& $2010 / 6 / 2$ & $2010 / 8 / 25$ & & & 5.47 & 7.03 \\
Post-M & & & \\
Winter & $2009 / 8 / 26$ & $2009 / 11 / 28$ & 607.17 & 46.00 & -3.93 & 8.19 \\
Pre-M $^{\mathrm{b}}$ & $2009 / 11 / 29$ & $2010 / 2 / 24$ & 603.62 & 26.91 & 3.69 & 7.86 \\
\hline
\end{tabular}

${ }^{\mathrm{a}}$ Post-monsoon.

${ }^{\mathrm{b}}$ Pre-monsoon. 


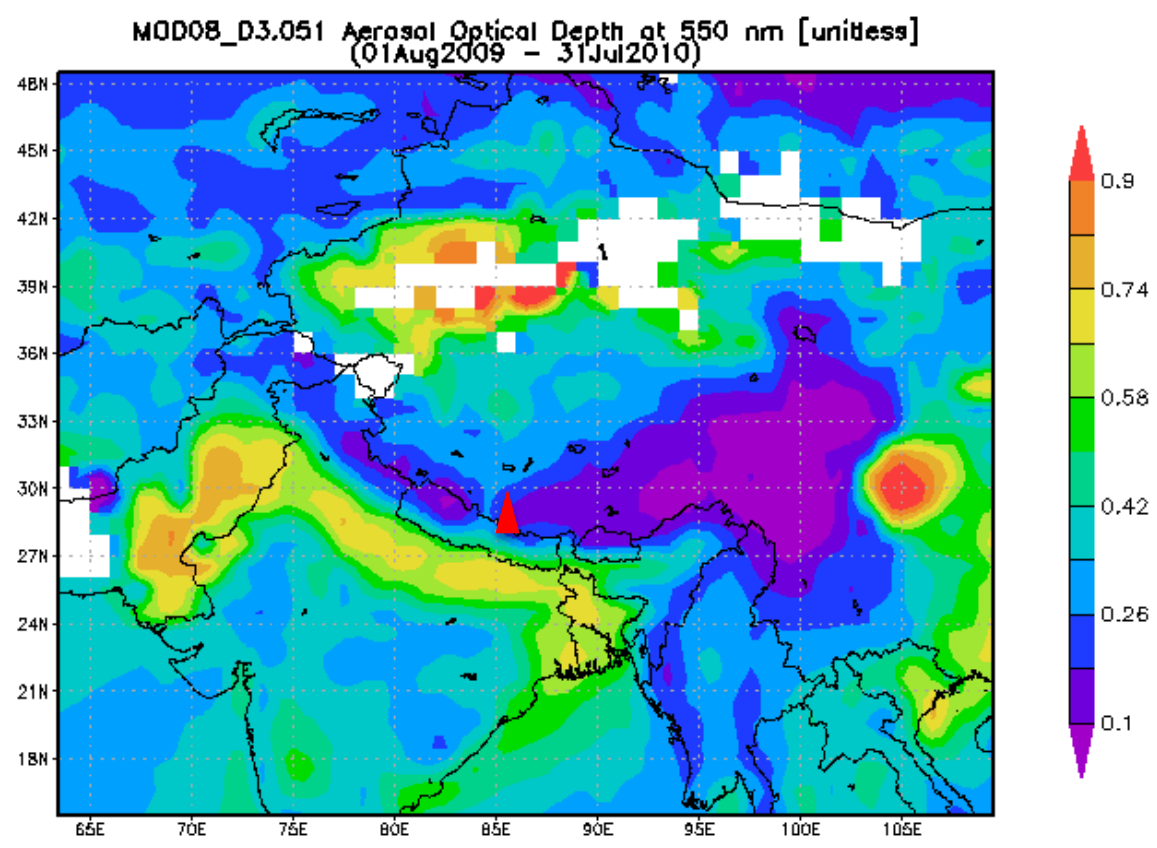

Fig. S1 The spatial distribution of aerosol optical depth at $550 \mathrm{~nm}$ based on MODIS Terra data, showing the distinctness between the Tibetan Plateau and South Asia in terms of aerosol loading (The graph was produced with the Giovanni online data system, NASA GES DISC). 


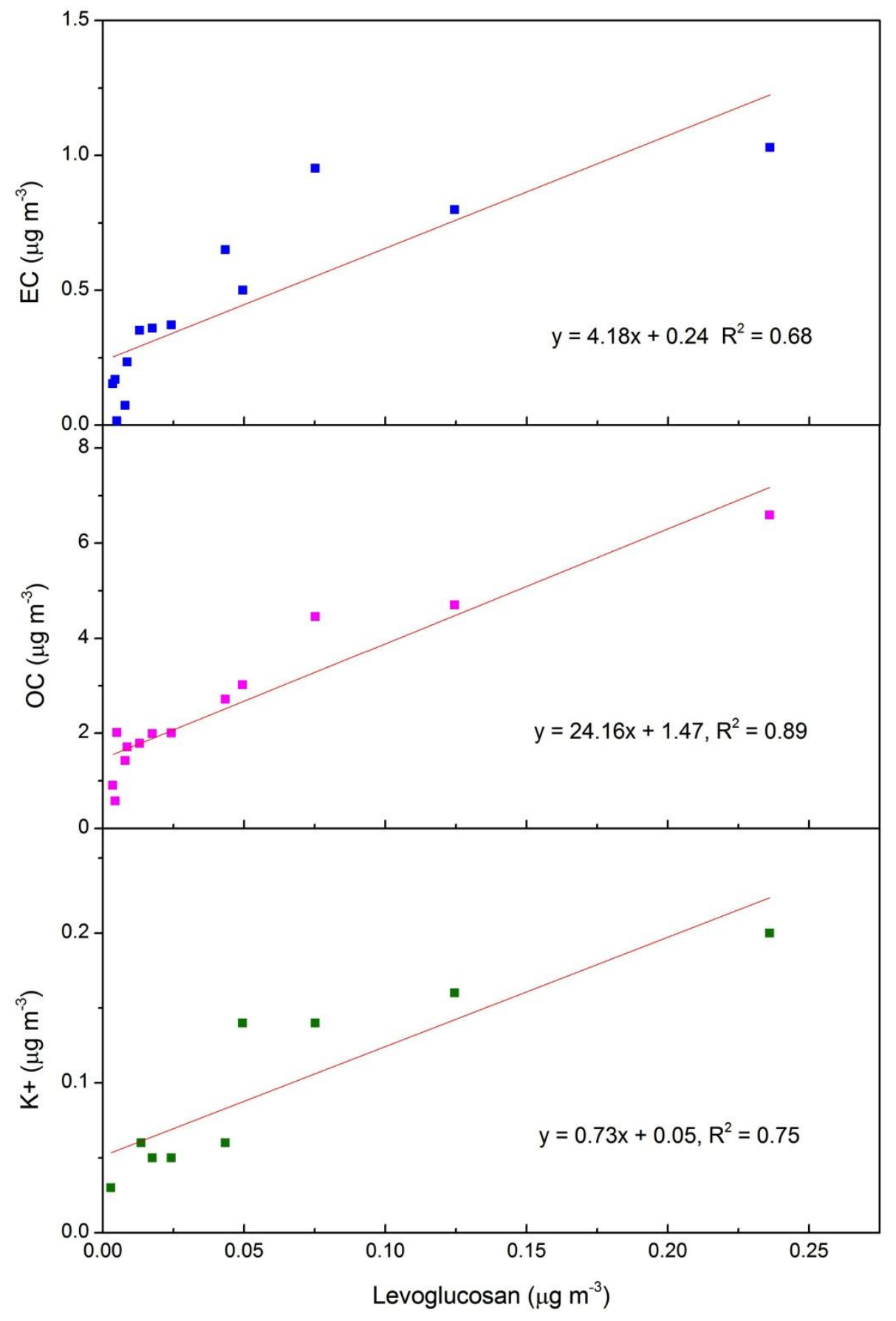

Fig. S2. The relationship between EC, OC, $\mathrm{K}^{+}$and levoglucosan in aerosols at QOMS (the data for levoglucosan was not presented in this manuscript). 


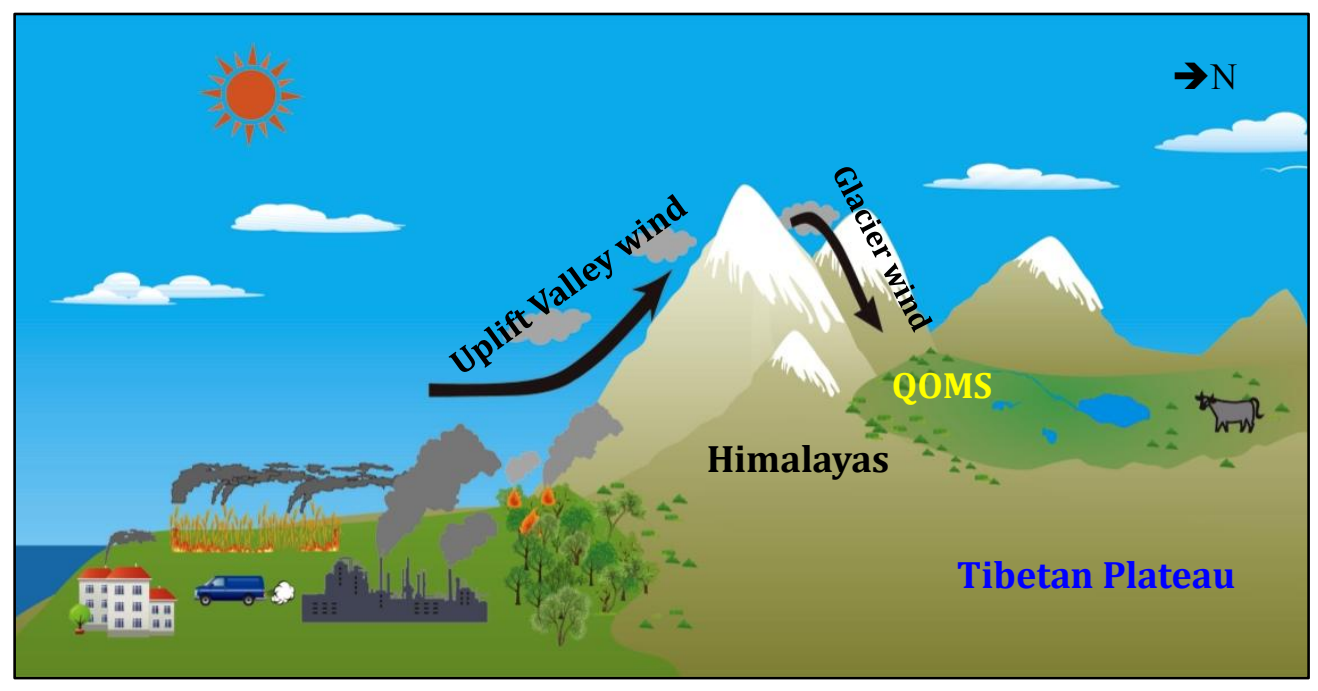

Fig. S3. Illustration of the aerosol transport mechanism from lowland of South Asia to across the Himalayas by the mountain/valley wind system. 